\title{
AMBIÊNCIA AÉREA EM ALOJAMENTO DE FRANGOS DE CORTE: POEIRA E GASES
}

\section{IRENILZA DE A. NÄ̈̈S ${ }^{1}$, MIWA Y. MIRAGLIOTTA ${ }^{2}$, MARTA DOS S. BARACHO ${ }^{3}$, DANIELLA J. DE MOURA ${ }^{4}$}

\begin{abstract}
RESUMO: A qualidade do ar em ambientes de produção animal vem sendo referenciada como ponto de interesse em estudos de sistema de controle ambiental, focando tanto a saúde dos animais que vivem em total confinamento, quanto a dos trabalhadores. $O$ objetivo do trabalho foi determinar a variação da qualidade da ambiência aérea em dois tipos de galpões criatórios de frangos de corte: convencional $\left(\mathrm{G}_{\mathrm{c}}\right)$ e tipo túnel $\left(\mathrm{G}_{\mathrm{t}}\right)$. Os valores de poeira total, em ambos os galpões, ofereceram condições adequadas às aves; entretanto, as concentrações de poeira respirável no ar estiveram acima do limite recomendado para humanos. A concentração de monóxido de carbono, na fase de aquecimento, esteve acima dos $10 \mathrm{ppm}$ máximos recomendados, no período avaliado, sendo superior na época de frio no galpão $G_{t}(30 \mathrm{ppm})$, comparada ao galpão $G_{c}(18$ ppm). Os picos de concentração de amônia no ar estiveram acima dos 20 ppm máximos recomendados às aves a partir do $20^{\circ}$ dia de produção, em ambos os galpões, e na média diária, por período superior no galpão $\mathrm{G}_{\mathrm{t}}(4 \mathrm{~h} 30)$, quando comparado ao $\mathrm{G}_{\mathrm{c}}(2 \mathrm{~h} 45)$. Foram encontrados apenas traços de óxido nítrico e metano, enquanto a concentração de gás carbônico, avaliada em condições diurnas, atendeu aos limites máximos permitidos, tanto para aves quanto para o trabalhador.
\end{abstract}

PALAVRAS-CHAVE: avicultura de corte, poluentes aéreos, saúde do trabalhador.

\section{AERIAL ENVIRONMENT IN BROILER HOUSING: DUST AND GASES}

\begin{abstract}
Air quality in animal production environment has been refereed as an interesting point for studies in environmental control systems with the focus both to the animal health which live in total confinement, as to the workers. The objective of this research was to determine the variation on the aerial environmental quality in two types of broiler housing: conventional $\left(\mathrm{G}_{\mathrm{c}}\right)$ and tunnel type $\left(\mathrm{G}_{\mathrm{t}}\right)$. The total dust values in both houses offered adequate rearing conditions to the birds; however, regarding the inhale dust in the air was above the limits recommended for humans. Carbon monoxide concentration in the heating phase during the evaluated period was above the $10 \mathrm{ppm}$ maximum recommended, and it was higher during the cold season in $\mathrm{G}_{\mathrm{t}}$ house (30 ppm) when compared to the $\mathrm{G}_{\mathrm{c}}$ house (18 ppm). Ammonia concentration peaks in the air were above the $20 \mathrm{ppm}$ recommended from the $20^{\text {th }}$ day of production in both houses and in daily average, for a period higher in $G_{t}(4 h 30)$ when compared to $G_{t}(2 h 45)$. Only traces of nitrate oxide and methane were found while carbonic dioxide gas concentration evaluated during daytime met the limits allowed for both birds and labor.
\end{abstract}

KEYWORDS: broiler production, aerial pollutant, worker health.

\section{INTRODUÇÃO}

A qualidade do ar em ambientes de produção animal vem sendo referenciada como ponto de interesse em estudos de sistema de controle ambiental, focando tanto a saúde dos animais que vivem em total confinamento, quanto a dos trabalhadores que permanecem de 4 a 8 horas por dia nesse ambiente de trabalho. Dentro do contexto da avicultura moderna, pesquisas mostram a influência direta do ambiente inadequado de criação como um dos fatores que predispõem ao

\footnotetext{
${ }^{1}$ Eng $^{\mathrm{o}}$ Civil, Profa. Voluntária, FEAGRI-UNICAMP, Caixa. Postal 6011, Campinas - SP.

${ }^{2}$ Médica Veterinária, Doutora em Engenharia Agrícola, FEAGRI-UNICAMP, Campinas - SP.

${ }^{3}$ Bióloga, Pesquisadora Voluntária, FEAGRI-UNICAMP, Campinas - SP.

${ }^{4}$ Eng $^{\mathrm{a}}$ Agrônoma, Profa. Dra., FEAGRI-UNICAMP, Campinas - SP.

Recebido pelo Conselho Editorial em: 13-11-2006

Aprovado pelo Conselho Editorial em: 13-4-2007
} 
desenvolvimento de doenças respiratórias nas aves (HYSLOP, 1974; SAINSBURY, 1981; CURTIS, 1983).

As doenças respiratórias em aves, geralmente resultado das condições inadequadas da qualidade do ar dentro do aviário, são a segunda maior causa de anormalidades que levaram à condenação total ou parcial de carcaças nos abatedouros (BRASIL, 1985; PINTO et al., 1993). Por outro lado, as referências sobre os poluentes dentro dos aviários e sua influência sobre a saúde animal, em sua grande maioria, são relacionadas à produção de frango em países de clima temperado, onde as construções são completamente fechadas e o resultado final do ambiente difere das condições brasileiras.

Existem quatro riscos básicos originados pela geração de poeiras ou particulados nas instalações de produção animal: a saúde do trabalhador, a saúde animal, a deterioração de equipamentos e das instalações, e a saúde dos vizinhos (DONHAM, 1999). No que se refere às condições ambientais para a produção animal, estudo detalhado realizado nos países escandinavos, com o objetivo de avaliar a composição da poeira, em galpões de frangos de corte em toda a fase criatória, com densidade média de $30-32 \mathrm{~kg} \mathrm{~m}^{-2}$, determinou as seguintes concentrações médias de particulados no ambiente aéreo: matéria-seca 911,0 $\pm 4,4 \mathrm{~g} \mathrm{~kg}^{-1}$; cinzas 97,4 $\pm 16,1 \mathrm{~g} \mathrm{~kg}^{-1}$; nitrogênio $169,0 \pm 2,3 \mathrm{~g} \mathrm{~kg}^{-1}$; fósforo $6,44 \pm 0,29 \mathrm{~g} \mathrm{~kg}^{-1}$; potássio $40,3 \pm 1,4 \mathrm{~g} \mathrm{~kg}^{-1}$; cloro $4,19 \pm$ $0,44 \mathrm{~g} \mathrm{~kg}^{-1}$ e sódio $3,23 \pm 0,34 \mathrm{~g} \mathrm{~kg}^{-1}$. A análise microscópica revelou que as amostras eram compostas, principalmente, de fragmentos de penas $(>10 \%)$ e cristais $(>10 \%$, sendo provavelmente cristais de urato), e secundariamente por ração $(<1 \%)$ e microrganismos e bolores $(<1 \%)$, não sendo encontrados fragmentos de excrementos nas amostras. A análise do tamanho das partículas revelou que os tamanhos de partículas mais freqüentes se encontravam nas faixas maiores que $9 \mu \mathrm{m}(61,4 \%)$ e entre $5,8-9,0 \mu \mathrm{m}(21,0 \%)$, e as demais faixas até $0,43 \mu \mathrm{m}$, representando 17,6\% das contagens efetuadas (AARNIK et al., 1999).

A concentração de poeira nos aviários apresenta uma das maiores médias, sendo de 3,83 a $10,4 \mathrm{mg} \mathrm{m}^{-3}$ para poeiras inaláveis e de 0,42 a $1,14 \mathrm{mg} \mathrm{m}^{-3}$ para poeiras respiráveis, quando comparadas às condições de produção de outras espécies (HARTUNG \& SEEDORF, 1999).

O CO (monóxido de carbono), resultante da queima incompleta do gás GLP, pode afetar os sistemas cardiovascular, nervoso central e reprodutivo das aves, quando presente em altas concentrações no ar. O CIGR (1989) recomenda o limite máximo de exposição de 10 ppm de CO para os animais. O limite mínimo de $\mathrm{O}_{2}$ é de $19,5 \%$, sendo normalmente encontrado na composição do ar atmosférico a 20,9\% (OSHA, 1994b).

MIRAGLIOTTA (2000), estudando a emissão de amônia em galpões de produção de frangos de corte, obteve maiores concentrações de amônia no ar e maiores índices de condenação total de carcaça por aerossaculite no sistema de produção em alta densidade $\left(18\right.$ aves $\left.\mathrm{m}^{-2}\right)$ com ventilação tipo túnel, na fase final de produção, comparado ao sistema convencional (13 aves $\mathrm{m}^{-2}$ e ventilação natural e mecanizada). No galpão em alta densidade, o terço final do galpão onde se realizava a exaustão do ar que percorria toda a instalação, apresentou maiores concentrações do gás amônia em decorrência do arraste do ar. No entanto, esse setor foi o que apresentou os menores índices de condenação de carcaça por aerossaculite no abatedouro. ABREU et al. (1998) determinaram os efeitos dos sistemas de aquecimento para criação de aves sobre os teores de água da cama-defrango e de amônia no ambiente. Os maiores teores de amônia foram encontrados nos sistemas em que eram utilizados forros e cortinas laterais, denominadas células, onde geralmente a umidade dentro dos círculos de proteção é maior, principalmente no horário de registro das $4 \mathrm{~h}$. As concentrações não ultrapassaram os $10 \mathrm{ppm}$, considerados seguros para a criação animal (CIGR, 1992).

HELLICKSON \& WALKER (1983) demonstraram que existe a tendência de difusão dos gases seguindo o fluxo de convecção do ar e que $\mathrm{CO}_{2}, \mathrm{NH}_{3}$ e $\mathrm{H}_{2} \mathrm{~S}$ são produzidos constantemente nas canaletas de esterco, sendo suas concentrações mais ou menos uniformemente distribuídas na instalação. Como fatores que intervêm na concentração de amônia nas construções, citam a 
influência da espécie alojada, da temperatura e da taxa de ventilação presente. Em criação de frangos de corte, mantidos a $24{ }^{\circ} \mathrm{C}$ e com taxa de ventilação de $1,1 \mathrm{~m}^{3} \mathrm{~h}^{-1}$ por ave, a concentração média encontrada pelos autores variou de 15 a $90 \mathrm{ppm}$. Dobrando-se essa taxa para $2,3 \mathrm{~m}^{3} \mathrm{~h}^{-1}$ por ave, reduziu-se a concentração para, no máximo, 50 ppm.

Considerando a importância do conhecimento das condições brasileiras de alojamento de frangos de corte, este trabalho teve como objetivo determinar a variação da qualidade da ambiência aérea em aviários ventilados de duas formas: ventilação tipo túnel e convencional.

\section{MATERIAL E MÉTODOS}

O estudo foi conduzido em granja comercial de frango de corte localizada na região de Rio Claro - SP, longitude $47^{\circ} 37^{\prime} 52^{\prime}$ ' W e latitude $22^{\circ} 24^{\prime} 54^{\prime}$ 'S, com ventos predominantes SE, em dois galpões dispostos lado a lado à distância de $30 \mathrm{~m}$ entre si, com as mesmas dimensões e características construtivas e orientação leste-oeste (Figura 1). Ambos os galpões tinham $12 \mathrm{~m}$ de largura por $120 \mathrm{~m}$ de comprimento, com pé-direito de $3,0 \mathrm{~m}$ e pilares de concreto a cada $8 \mathrm{~m}$, com tesouras de madeiras e telhado de fibrocimento. Para o correto funcionamento do sistema, o galpão $\mathrm{G}_{\mathrm{t}}$ recebeu vedação completa dos vãos, de forma a garantir a pressão negativa prevista em projeto, por meio da vedação das frestas (portas/paredes e cortinas/vigas) com o mesmo material das cortinas, e pela instalação de peças de vedação na junção da telha de fibrocimento (Canalete 90 Eternit $\left.{ }^{\circledR}\right)$, com as vigas do telhamento.

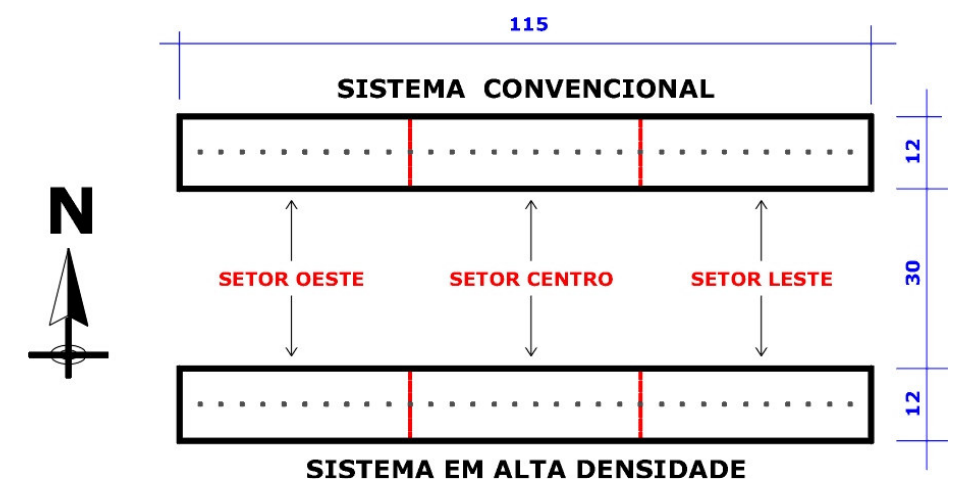

FIGURA 1. Esquema do posicionamento dos dois galpões utilizados no estudo (dimensões em m).

Devido à extensão dos galpões, cada um deles foi dividido em três setores iguais por meio de tela metálica de $5 \mathrm{~mm}$, instalada transversalmente, de maneira a impedir o trânsito dos frangos entre os setores. Cada um desses setores (oeste, centro e leste) foi dividido virtualmente em 11 faixas transversais para a delimitação da área de registro de dados, utilizando-se do posicionamento dos pilares (11 em cada setor) como orientação para essa divisão.

Para a coleta de poeira e gases, essas faixas foram divididas perpendicularmente em duas, originando 22 células de $6,0 \times 3,5 \mathrm{~m}$ por setor. No entanto, para a garantia da diferenciação das condições entre setores, foram descartadas as duas células de cada extremidade em cada setor, restando, então, 18 células centrais para a aleatorização do local de coleta dos dados por setor.

Para cada galpão, foi estabelecido um sistema de ventilação adequado à densidade de produção de frangos, calculado em função do balanço de carga térmica existente dentro de cada instalação.

No galpão ilustrado no esquema da Figura 2, estão associados: densidade convencional das aves (13 aves $\left.\mathrm{m}^{-2}\right)$; três linhas de bebedouros tipo "nipple" e duas linhas de comedouros automáticos; ventilação natural por manejo convencional de cortinas (cor amarela); ventilação forçada (seis ventiladores axiais tipo Tufão de $0,5 \mathrm{cv}$, com vazão de $300 \mathrm{~m}^{3} \mathrm{~min}^{-1}$ colocados a $120 \mathrm{~cm}$ do piso) na direção oeste-leste; sistema de nebulização longitudinal de média pressão e 
com bicos nebulizadores a cada $2 \mathrm{~m}$, dispostos em duas linhas, caracterizado como galpão convencional $\mathrm{G}_{\mathrm{c}}$.

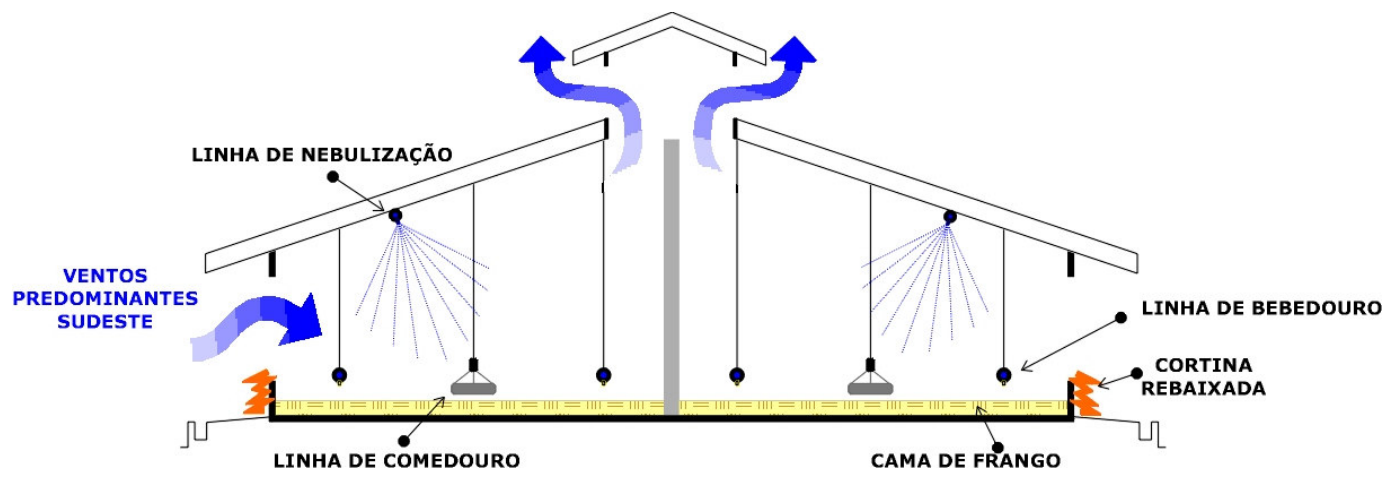

FIGURA 2. Corte transversal do galpão Gc em período de resfriamento.

No galpão ilustrado no esquema da Figura 3, estão associados: alta densidade de aves (18 aves $\mathrm{m}^{-2}$ ); quatro linhas de bebedouros tipo "nipple" e três linhas de comedouros automáticos; sistema de manejo convencional até o $25^{\circ}$ dia; sistema de ventilação tipo túnel, após o $25^{\circ}$ dia de produção, na direção leste-oeste, contendo oito exaustores de $1,5 \mathrm{cv}$ trifásicos, com vazão média de $10,5 \mathrm{~m}^{3} \mathrm{~min}^{-1}$, localizados na face leste (a $60 \mathrm{~cm}$ do piso); duas linhas de nebulização; controlador Climatic ${ }^{\circledR}$-I com duas etapas e um painel de potência. Nesse galpão, as cortinas das laterais eram impermeáveis e na cor azul, sendo suspensas a partir do $25^{\circ}$ dia de produção, quando as condições climáticas assim o exigissem, o que se deu por volta das $9 \mathrm{~h}$ às $18 \mathrm{~h}$. Associado a isso, o sistema de ventilação tipo túnel promoveu a passagem contínua de ar ao longo de todo o galpão na direção leste-oeste. Esse galpão foi nominado de $\mathrm{G}_{\mathrm{t}}$.

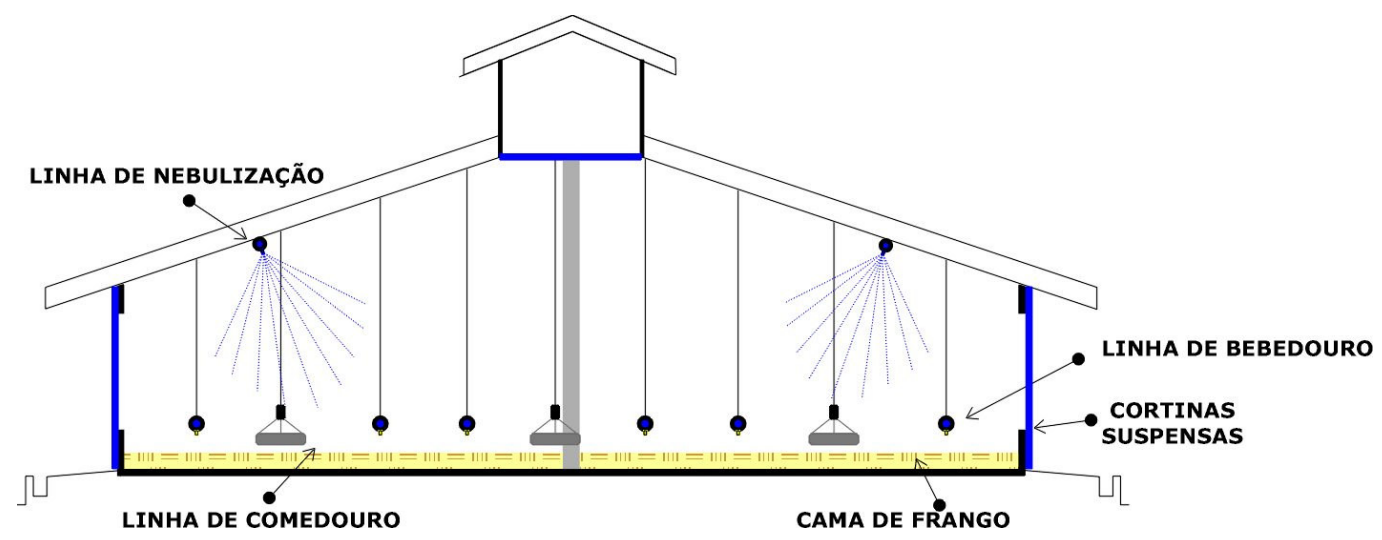

FIGURA 3. Corte transversal do galpão Gt em período de resfriamento.

A automatização desse sistema incluiu os exaustores da cabeceira oeste e o sistema de nebulização longitudinal, que promoveu o resfriamento adiabático do galpão. Para o correto funcionamento do sistema, o galpão recebeu vedação completa dos vãos e das frestas (portas/paredes e cortinas/vigas) com o mesmo material das cortinas, caracterizando o galpão $\mathrm{Gt}_{\mathrm{t}}$ como ventilação tipo túnel.

A avaliação da poeira foi feita por meio de coleta semanal do particulado suspenso no ar nos três setores dos dois galpões, na altura dos frangos. A coleta foi simultânea e semanal, para cada um dos parâmetros (poeira total e respirável) em cada setor dos galpões, para que fossem obtidos dados ao longo de toda a extensão da instalação. Foram utilizadas, para a coleta na altura das aves, seis bombas de amostragem (Gilair ${ }^{\circledR} 5$ com timer - Gillian ${ }^{\circledR}$ USA) dispostas a $0,50 \mathrm{~m}$ do nível da cama em cada setor dos dois galpões. A calibração de cada bomba de amostragem de ar foi 
realizada antes e depois de cada coleta, seguindo-se os passos recomendados pelo fabricante. Os dois parâmetros de concentração de poeira no ar seguiram as seguintes recomendações: poeira total, método 0500 (OSHA, 1994a), e poeira respirável, método 0600 (OSHA, 1994b).

Para a avaliação da concentração dos gases $\mathrm{O}_{2}$ (oxigênio), $\mathrm{NH}_{3}$ (amônia) e $\mathrm{CO}$ (monóxido de carbono) para o período de aquecimento (0 ao $14^{\circ}$ dia de produção) e $\mathrm{O}_{2}, \mathrm{NH}_{3}, \mathrm{CH}_{4}$ (metano) e $\mathrm{NO}$ (óxido nítrico) para o período de resfriamento ( $15^{-}$ao final), foram utilizados três monitores de gases (Multilog 2000, Quest ${ }^{\circledR}$ ) configurados para leitura contínua a cada segundo e com armazenamento das médias a intervalos de $15 \mathrm{~min}$. Para a garantia da precisão das leituras, foi usada a calibragem prévia a cada lote de produção, utilizando-se de gases de calibração-padrão (White Martins ${ }^{\circledR}$ ) sob as mesmas condições de pressão atmosférica do ar.

Para avaliação da concentração de $\mathrm{CO}_{2}$ no ambiente interno do galpão, foram coletadas amostras de ar instantâneas a $50 \mathrm{~cm}$ de altura do piso, em cada setor dos dois galpões, na última semana de produção, utilizando-se de bomba de sucção e tubos colorimétricos (Dräger® para $\mathrm{CO}_{2}$ $(100-3.000 \mathrm{ppm}))$.

Os horários de armazenamento foram sincronizados com o registro de dados bioclimáticos, a cada $15 \mathrm{~min}$, totalizando quatro leituras por hora. Ao final do lote, os dados foram transferidos para o computador e analisados em software próprio.

Os equipamentos foram posicionados a $0,50 \mathrm{~m}$ do nível da cama, dentro de gaiola metálica, no centro geométrico do pinteiro (na fase de aquecimento) e no centro geométrico da mesma célula de cada setor (no período de engorda) e foram dispostos de modo a permanecerem três dias no galpão Gc e três dias no galpão Gt, na mesma semana. Os dados foram registrados no período de julho a dezembro de 2004.

Para a análise estatística, a cada lote, foi realizada a aleatorização do setor onde foram posicionados os equipamentos de registro das variáveis. Semanalmente, foi determinado por sorteio o setor onde ocorreriam as coletas pareadas de gases e poeira, além da escolha dos equipamentos a serem utilizados em cada galpão. A avaliação dos parâmetros foi feita, inicialmente, verificando-se a normalidade da distribuição dos dados, fato esse não observado para a maioria deles, optando-se por comparação de medianas e por testes não-paramétricos de Mann-Whitney ou Kruskal-Wallis. A inter-relação entre variáveis foi realizada por meio de análises de correlação e regressões.

\section{RESULTADOS E DISCUSSÃO}

\section{Concentração de poeira no ar}

Os resultados de avaliação da concentração de poeira foram obtidos dos lotes 1 a 10 e agrupados por semana para o teste de normalidade de Anderson-Darling, uma vez que não apresentaram distribuição normal dos seus dados. Pelo teste não-paramétrico de Kruskal-Wallis, não foram observadas diferenças significativas a $5 \%$ entre as medianas da concentração de poeira total dos dois galpões ( $\mathrm{p}$-valor $=0,078$ ), em função da grande variabilidade observada nos resultados para um mesmo dia. O galpão $\mathrm{G}_{c}$ apresentou mediana de $0,84 \mathrm{mg} \mathrm{m}^{-3}$ e máxima de $2,50 \mathrm{mg} \mathrm{m}^{-3}$ no $35^{\mathrm{o}}$ dia de produção, enquanto o galpão $\mathrm{Gt}$ apresentou os valores de $1,25 \mathrm{mg} \mathrm{m}^{-3} \mathrm{e}$ máxima de $2,26 \mathrm{mg} \mathrm{m}^{-3}$, respectivamente, no $33^{0}$ dia de produção. Esses valores são inferiores aos encontrados em condições temperadas de produção, em galpões fechados e com ambiente controlado, relatados por HARTUNG \& SEEDORF (1999), em que a concentração de poeira inalável, fração $<100 \mu \mathrm{m}$ da poeira total, variou de 3,83 a $10,4 \mathrm{mg} \mathrm{m}^{-3}$ e por TAKAI et al. (1999), em que as médias da poeira inalável se encontravam em torno de 3,60 $\mathrm{mg} \mathrm{m}^{-3}$, em aviários para produção de frangos de corte e poedeiras.

Além do fator clima, que influi consideravelmente sobre os resultados de concentração de poeira, promovendo maior ou menor suspensão dos particulados, devem ser considerados a tipologia construtiva, o sistema de ventilação e o material que compõe a cama-de-frango, como diferenciais para a comparação de condições de produção em países de clima temperado e tropical. 
Em termos de limites de tolerância internacionais, que abrangem todas as categorias de trabalho visando a atender à saúde humana, quando se confrontam esses resultados obtidos em galpões de produção de frango, observa-se ainda assim valores inferiores às máximas permitidas pela NIOSH (OSHA, 1994a), de $15 \mathrm{mg} \mathrm{m}^{-3}$, e pela ACGIH (2001), de $10 \mathrm{mg} \mathrm{m}^{-3}$.

As concentrações de poeira total no ar tenderam ao crescimento ao longo do lote nos dois galpões, mas apresentaram maior variação nos valores para um mesmo dia, no galpão Gt. O número de aves em movimento e o sistema de ventilação diferenciado, com velocidade de ar maior no galpão $\mathrm{Gt}_{\mathrm{t}}\left(1,50 \mathrm{~m} \mathrm{~s}^{-1}\right)$ do que no $\mathrm{G}_{\mathrm{c}}\left(0,39 \mathrm{~m} \mathrm{~s}^{-1}\right)$, podem estar relacionados a esses resultados. A grande variabilidade dos resultados é fator considerado na metodologia de avaliação de particulados por gravimetria.

Pelo teste não-paramétrico de Kruskal-Wallis, foram observadas diferenças significativas a $5 \%$ entre as medianas da concentração de poeira respirável dos dois galpões ( $\mathrm{p}$ valor $=0,008$ ), sendo maior no galpão $\mathrm{G}_{c}$, com mediana de $0,42 \mathrm{mg} \mathrm{m}^{-3}$, e máxima de $1,78 \mathrm{mg} \mathrm{m}^{-3}$, no $31^{\circ}$ dia de produção, do que no galpão Gt, cuja mediana obtida foi de $0,08 \mathrm{mg} \mathrm{m}^{-3}$ e máxima de $1,10 \mathrm{mg} \mathrm{m}^{-3}$, no $21^{\circ}$ dia de produção. Esses resultados encontram-se adequados aos limites estabelecidos de $3 \mathrm{mg} \mathrm{m}^{-3}$ pelas normas internacionais da ACGIH (2001) e $5 \mathrm{mg} \mathrm{m}^{-3}$ pela OSHA (1994b). No entanto, confrontando-se esses resultados com estudos em condições semelhantes, nota-se que se encontram na mesma faixa de valores obtidos em produções de aves em climas temperados, de 0,42 a 1,14 $\mathrm{mg} \mathrm{m}^{-3}$ (HARTUNG \& SEEDORF, 1999) e 0,45 $\mathrm{mg} \mathrm{m}^{-3}$ (TAKAI et al., 1993) e acima dos limites dose-resposta estabelecidos por DONHAM (1999) para o trabalhador rural, de $0,16 \mathrm{mg} \mathrm{m}^{-3}$.

Os resultados de coletas simultâneas de poeira total para comparativo de diferenças entre setores, na quinta semana de produção, mostraram que o setor centro do galpão Gt apresentou maior concentração de poeira total de todos os setores avaliados. Os setores do galpão $\mathrm{G}_{c}$ apresentaram valores semelhantes para o mesmo dia (Figura 4).

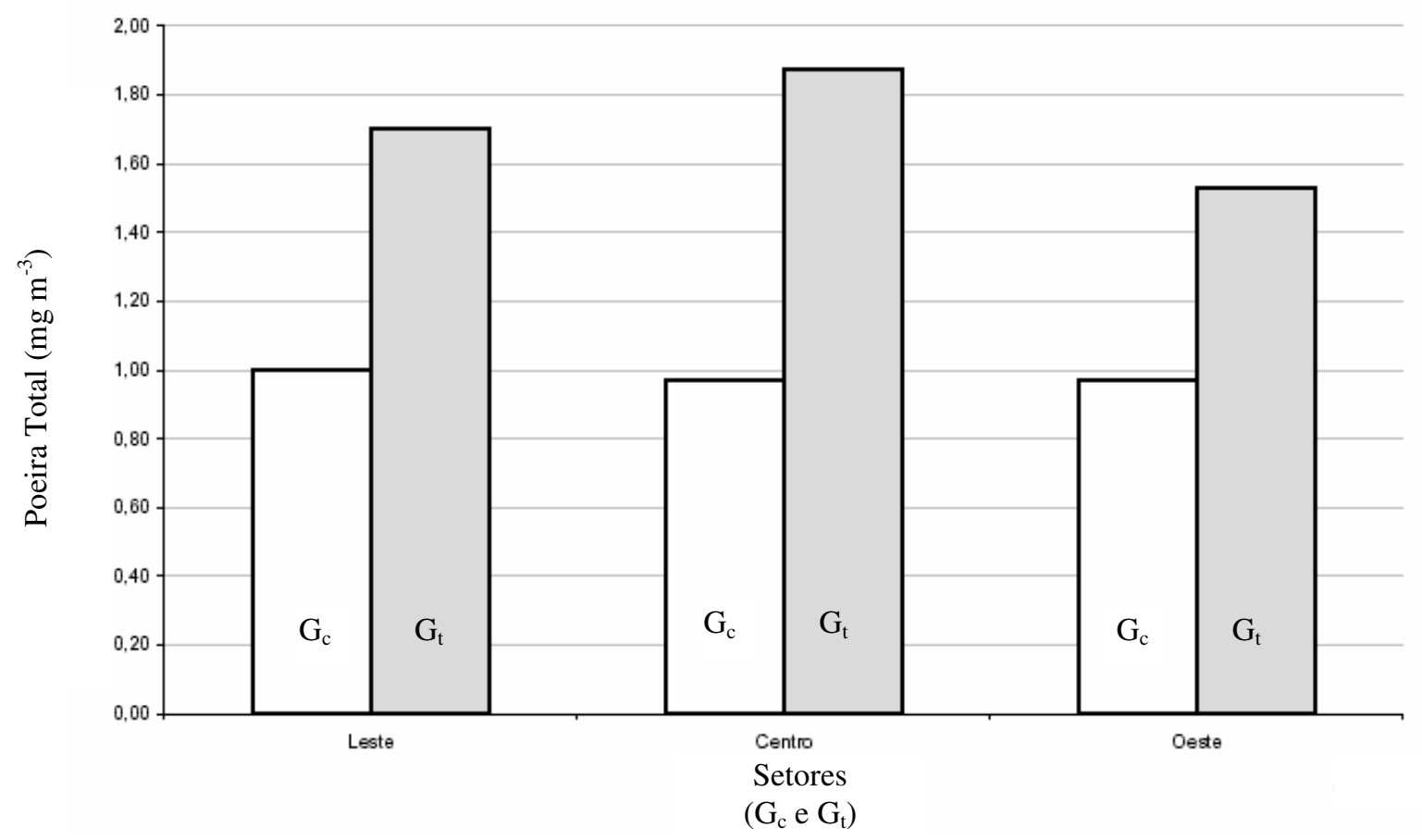

FIGURA 4. Resultados de coleta simultânea de poeira total nos três setores de ambos os galpões, na quinta semana de produção. 


\section{Concentração de gases no interior dos galpões}

\section{Monóxido de carbono}

Os resultados da avaliação simultânea, em três pinteiros, podem ser observados na Tabela 1. A temperatura externa média foi de $23,60{ }^{\circ} \mathrm{C}$ com mínima de $19,72{ }^{\circ} \mathrm{C}$. Não foram observadas diferenças significativas $(\mathrm{p}<0,05 \%)$ entre as temperaturas de bulbo seco (TBS) dos galpões com pinteiros separados, assim como nas velocidades do ar dos galpões, que se mantiveram nos níveis de "ventilação sanitária", sem rajadas de vento.

TABELA 1. Resultados da coleta simultânea dentro dos galpões.

\begin{tabular}{ccccc}
\hline Galpão & TBS & UR & $\mathrm{O}_{2}$ & $\mathrm{CO}$ \\
\hline $\mathrm{G}_{\mathrm{c}}$ & 24,55 & $78,40^{*}$ & $20,88^{*}$ & $40,78^{*}$ \\
$\mathrm{G}_{\mathrm{t}}$ & $24,93 \mathrm{e} 28,50^{*}$ & $82,24^{*} \mathrm{e} 68,68^{*}$ & $20,74^{*} \mathrm{e} 20,53$ & $80,00^{*} \mathrm{e} 105,90^{*}$ \\
\hline
\end{tabular}

TBS - temperatura de bulbo seco do ar $\left({ }^{\circ} \mathrm{C}\right)$; UR = umidade relativa do ar $(\%) ; \mathrm{O}_{2}$ - concentração do oxigênio no ar (\%) e CO - concentração de monóxido de carbono no ar (ppm).

* Diferem pelo Teste F de Fisher $(\mathrm{p}<0,05)$.

Obs: Foram feitas duas coletas em $\mathrm{G}_{\mathrm{t}}$.

As médias de TBS, de $24,55{ }^{\circ} \mathrm{C}$ (Gc) e $24,93{ }^{\circ} \mathrm{C}$ (galpão $\mathrm{G}_{\mathrm{t}}$ ), estão abaixo da temperatura recomendada de $33{ }^{\circ} \mathrm{C}$, no quarto dia de produção. No segundo lote do galpão $\mathrm{G}_{\mathrm{t}}$, a maior média de TBS $\left(28,50{ }^{\circ} \mathrm{C}\right)$ e a menor média de UR do ar $(68,68 \%)$ sugerem melhores condições de conforto térmico dos pintinhos, embora a maior média de concentração de CO (105,90 ppm) e, conseqüentemente, menor média de $\mathrm{O}_{2}$ no ar (20,53\%), resulta em pior qualidade do ar, comparados aos demais sistemas. As concentrações médias de $\mathrm{CO}$ no ar encontradas nos galpões são superiores aos limites máximos recomendados pelo CIGR (1992) para os animais.

Os valores médios de $\mathrm{CO}$ no ar mostram que a queima do gás GLP nos aquecedores se processou de forma incompleta, mesmo após a regulagem dos bicos de gás das campânulas. Para as condições de $\mathrm{G}_{\mathrm{t}}$, a TBS interna manteve-se, em média, cerca de $4,5{ }^{\circ} \mathrm{C}$ acima das condições noturnas externas, porém não atingiu, em nenhum dos dias analisados, a temperatura recomendada para pintinhos (CONY \& ZOCCHE, 2004), estando, em média, cerca de $8^{\circ} \mathrm{C}$ abaixo do ideal.

\section{Amônia}

A análise estatística descritiva inicial mostrou que os dados obtidos, tanto para o galpão convencional $\left(\mathrm{G}_{\mathrm{c}}\right)$ quanto para o tipo túnel $\left(\mathrm{G}_{\mathrm{t}}\right)$, não apresentaram distribuição normal segundo Teste de Normalidade de Anderson-Darling. A comparação das medianas indicou maior dispersão dos dados de concentração de amônia (ppm) no galpão convencional $\left(\mathrm{G}_{\mathrm{c}}\right)$, sendo a média posicionada acima do intervalo de confiança da mediana, como resposta ao grande número de outliers observados. Comparativamente, os dados de $\mathrm{G}_{\mathrm{t}}$ apresentaram-se mais uniformemente distribuídos.

Os resultados da análise dos dados por métodos não-paramétricos (teste de Mann-Whitney) indicam que a concentração de amônia $(\mathrm{ppm})$ no galpão $\mathrm{G}_{\mathrm{t}}$ mostrou-se significativamente superior à do galpão $\mathrm{G}_{\mathrm{c}}(\mathrm{p}<0,05)$ com medianas de $3 \mathrm{ppm}$ e $0 \mathrm{ppm}$, respectivamente. Da observação do perfil da concentração de amônia ( $\mathrm{ppm}$ ), constatou-se que os valores foram inferiores a $20 \mathrm{ppm}$, limite máximo recomendado pela CIGR (1984), até o 19ํํำ dia de produção, em ambos os galpões. Cabe ressaltar que parte das medições foi realizada durante o período noturno nas duas primeiras semanas (0 - 14ํํㄹ dia de produção), para a avaliação da qualidade do ar resultante da queima do gás GLP pelas campânulas de aquecimento dos pintinhos.

Durante a fase de aquecimento, do dia 0 ao $14^{0}$ dia de produção, as máximas obtidas foram de 13 ppm para $G_{c}$ e 17 ppm para $G_{t}$, ambos às $13 \mathrm{~h} 15$ do sexto dia de produção, diferindo dos resultados obtidos por ABREU et al. (1998), que observaram valores máximos (10 ppm) durante o período da madrugada $(4 \mathrm{~h})$. Os valores médios encontrados por MIRAGLIOTTA (2000), nesses mesmos galpões, foram de 0,49 ppm para $G_{c}$ e 1,69 ppm para $G_{t}$, no $14^{-}$dia de produção. $O$ teste 
comparativo não-paramétrico determinou que, para esse primeiro período, não existiu diferença significativa $(\mathrm{p}>0,05)$ na concentração de amônia no ar $(\mathrm{ppm})$, nas condições estudadas entre os galpões $\mathrm{G}_{\mathrm{c}}$ e $\mathrm{G}_{\mathrm{t}}$.

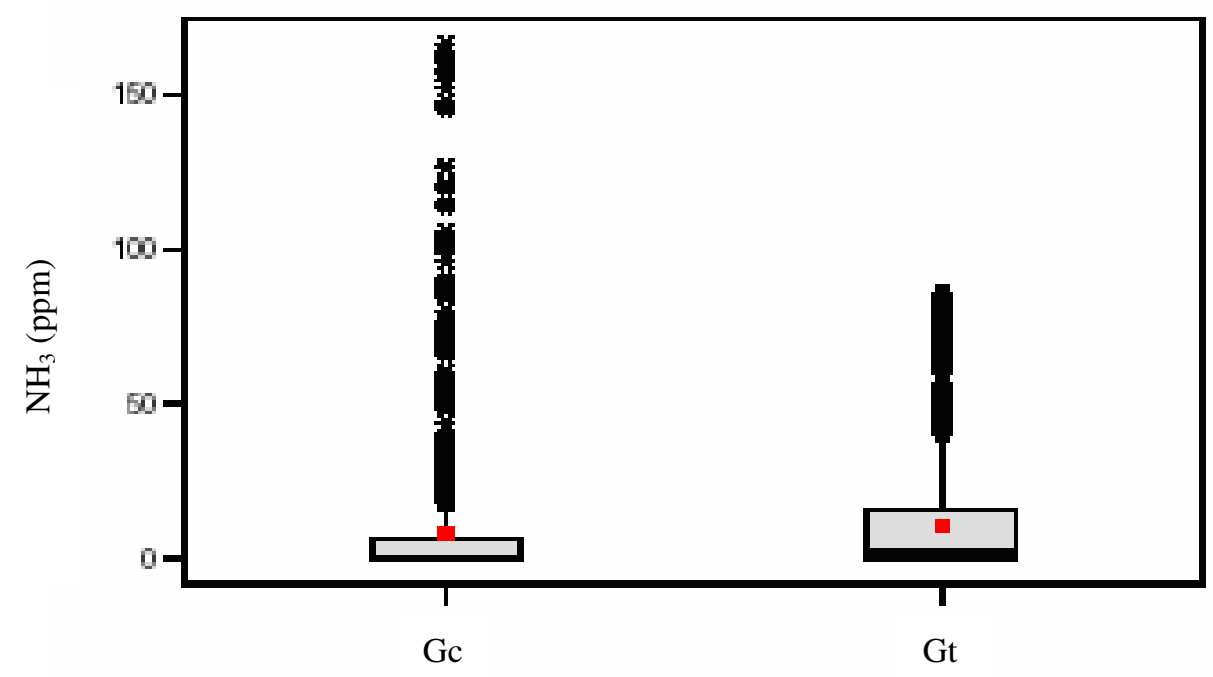

FIGURA 5. Boxplot dos dados de concentração de amônia (ppm) ao longo do lote de produção para os dois galpões $\left(\mathrm{G}_{\mathrm{c}}\right.$ e $\left.\mathrm{G}_{\mathrm{t}}\right)$.

Para o período de engorda das aves, observando-se o padrão de não-normalidade dos dados, resultaram concentrações máximas obtidas de $167 \mathrm{ppm}$ para o galpão $\mathrm{G}_{\mathrm{c}}$ e $86 \mathrm{ppm}$ para $\mathrm{G}_{\mathrm{t}}$, valores elevados para as recomendações internacionais. $\mathrm{O}$ teste comparativo não-paramétrico mostrou que existe diferença altamente significativa $(\mathrm{p}<0,01)$ entre galpões, sendo superior no galpão $\mathrm{G}_{\mathrm{t}}$.

\section{Outros gases}

Foram encontrados somente traços de $\mathrm{NO}$ e $\mathrm{CH}_{4}$ nas fases finais. Uma das possíveis razões para baixas concentrações de metano em galpões de produção de frangos de corte seria o crescimento mais demorado das bactérias metanogênicas no processo de degradação da cama-defrango (PAULA JÚNIOR, 2004). Esses valores indicam a pouca sensibilidade do equipamento para detecção de baixas concentrações desses gases. O olfato humano tem a capacidade de detecção de alguns gases, na ordem de ppb (parte por bilhão), e o equipamento utilizado neste estudo (MULTILOG ${ }^{\circledR}$ 2000) tem a capacidade de detecção a partir de ppm (parte por milhão).

Para a avaliação da concentração de $\mathrm{CO}_{2}$, foram tomadas medidas aleatórias durante alguns dias em lotes diversos e em todas as ocasiões, sendo a concentração igual ou inferior a 1.000 ppm no ar. Como a concentração habitual de $\mathrm{CO}_{2}$ na atmosfera se encontra entre 500 e 750 ppm, os valores encontrados do gás não representaram situações de risco, tanto para os animais quanto para os trabalhadores, visto que, para ambas as situações, o limite máximo está situado em 3.000 ppm e $5.000 \mathrm{ppm}$, respectivamente.

\section{CONCLUSÕES}

Os valores de poeira total obtidos em ambos os galpões indicam que os mesmos ofereceram condições adequadas às aves, entretanto as concentrações de poeira respirável no ar estão acima do limite recomendado para humanos. A concentração de monóxido de carbono observada nos aviários, na fase de aquecimento das aves, esteve acima dos 10 ppm máximos recomendados, em todo o período avaliado, sendo superior na época de frio e no galpão com sistema de ventilação tipo túnel (30 ppm), quando comparado ao galpão com ventilação convencional (18ppm).

Os picos de concentração de amônia no ar estiveram acima dos 20 ppm, máximo recomendado às aves a partir do $20^{\circ}$ dia de produção, em ambos os galpões e na média diária, por 
período superior no galpão com ventilação tipo túnel (4h30), quando comparado ao galpão com ventilação convencional ( $2 \mathrm{~h} 45)$.

Foram encontrados apenas traços de óxido nítrico e metano, enquanto a concentração de gás carbônico, avaliada em condições diurnas, atendeu aos limites máximos permitidos, tanto para as aves quanto para os trabalhadores.

\section{AGRADECIMENTOS}

Os autores agradecem à FAPESP, pelo apoio à pesquisa.

\section{REFERENCIAS}

AARNIK, A.J.A.; ROELOFS, P.F.M.M.; ELLEN, H.; GUNNIK, H. Dust Sources in Animal Houses. In: INTERNATIONAL SYMPOSIUM ON DUST CONTROL IN ANIMAL PRODUCTION FACILITIES, 1., 1999, Aarhus. Proceedings... Aarhus: Danish Institute of Agricultural Sciences, 1999. p 34-40.

ABREU, P.G.; BAÊTA, F.C.; ABREU, V.M.N.; SOARES, P.R.; PERDOMO, C.C.; SILVA, M.A. Umidade da cama e teor de amônia em diferentes sistemas de aquecimento de frangos de corte. In: CONFERÊNCIA APINCO, 16., 1998, Campinas. Anais... Campinas: Fundação Apinco de Ciência e Tecnologias Avícolas, 1998. p.68.

ACGIH. AMERICAN CONFERENCE OF GOVERNMENTAL INDUSTRIAL HYGIENISTS. TLVs and BEIs - Handbook . Cincinnati: ACGIH, 2001. 132 p.

BRASIL. MINISTÉRIO DA AGRICULTURA. Boletim Estatístico SERPA/SP. São Paulo: Delegacia Federal de Agricultura de São Paulo. 1985. 28 p. (Boletim Técnico).

CIGR. COMISSION INTERNATIONALE DU GÉNIE RURAL. Climatization of animal houses. $1^{\text {st }}$ Report of Working Group. Aberdeen: Scottish Farm Buildings Investigation Unit, 1984. 56 p.

CIGR. COMMISSION INTERNATIONALE DU GÉNIE RURAL. Climatization of animal houses. $2^{\text {nd }}$ Report of Working Group-Revision. Aberdeen: Scottish Farm Buildings Investigation Unit, 1989. $64 \mathrm{p}$.

CIGR. COMMISSION INTERNATIONALE DU GÉNIE RURAL. Climatization of animal houses. Final Report of Working Group. Aberdeen: Scottish Farm Buildings Investigation Unit, 1992. $58 \mathrm{p}$.

CONY, AV.; ZOCCHE, A.T. Instalações e equipamentos. In: CONFERÊNCIA APINCO DE CIÊNCIA E TECNOLOGIAS AVÍCOLAS, 19., 2001, Campinas. Anais... Campinas: Fundação Apinco de Ciência e Tecnologias Avícolas, 2001. v.2, p.33-50.

CURTIS, S.E. Environmental management in animal agriculture. Iowa: Iowa State University Press, 1983. $650 \mathrm{p}$.

DONHAM, K. A historical overview of research on the hazards of dust in livestock buildings. In:

INTERNATIONAL SYMPOSIUM ON DUST CONTROL IN ANIMAL PRODUCTION

FACILITIES, 1., 1999. Aarhus, Proceedings... Aarhus: Danish Institute of Agricultural Sciences, 1999. p.13-21.

HARTUNG, J.; SEEDORF, J. Characterization of airborne dust in livestock housing and its effects on animal and environment. In: INTERNATIONAL SYMPOSIUM ON DUST CONTROL IN ANIMAL PRODUCTION FACILITIES, 1., 1999, Aarhus. Proceedings... Aarhus: Danish Institute of Agricultural Sciences, 1999. p.140-53.

HELLICKSON, M.A.; WALKER, J.N. Ventilation of agricultural structures. St. Joseph: American Society of Agricultural Engineers, 1983. 213 p. 
HYSLOP, N.S.G. Effects of the environment on immunity to disease. In: LIVESTOCK ENVIRONMENT, 1., 1974, Lund. Proceedings... St. Joseph: American Society of Agricultural Engineers, 1974. p.383-90.

MIRAGLIOTTA, M.Y. Avaliação dos níveis de amônia em dois sistemas de produção de frangos de corte com ventilação e densidade diferenciados. 2000. 122 f. Dissertação (Mestrado em Construções Rurais e Ambiência) - Faculdade de Engenharia Agrícola, UNICAMP, Campinas, 2000.

OSHA. OCCUPATIONAL SAFETY AND HEALTH ADMINISTRATION. Particulates not otherwise regulated, total 0500- Manual of Analytical Methods (NMAM). $4^{\text {th }}$.ed. USA: NIOSH. 1994 (a). Disponível em http://www.cdc.gov/niosh/nmam/nmammenu.html. Acesso em: 7 maio 2002.

OSHA. OCCUPATIONAL SAFETY AND HEALTH ADMINISTRATION. Particulates not otherwise regulated, respirable 0600. Manual of Analytical Methods (NMAM). 4.ed. USA: NIOSH. 1994(b). Disponível em http://www.cdc.gov/niosh/nmam/nmammenu.html. Acesso em: 7 maio 2002.

PAULA JÚNIOR, D.R. Biodigestores: tecnologia de processos anaeróbios para tratamento de resíduos agroindustriais. Campinas: Faculdade de Engenharia Agrícola, 2004. 16 p. Apostila

PINTO, F.G.; CURI, P.R.; TOLEDO, M. Evolução da condenação avícola no Estado de São Paulo (1985 a 1990): tendências anuais e estacionais. Veterinária e Zootecnia, São Paulo, v.5, p.45-50, 1993.

SAINSBURY, D.W.B. Health problems in intensive animal production. In: CLARK, J.A. Environmental aspects of housing for animal production. Butterworths: England, 1981. p.439-54.

TAKAI, H.; MÖLLER, F.; IVERSEN, M.; JORSAL, S.E.; BILLE-HANSEN, V. Dust control in swine buildings by spraying of rapeseed oil. In: LIVESTOCK ENVIRONMENT SYMPOSIUM, 4., 1993, St. Joseph. Proceedings... St Joseph: American Society of Agricultural Engineering, 1993. p.726-33.

TAKAI, H.; SEEDORF, J.; PEDERSEN, S. Dust and endotoxin concentrations in livestock buildings in norther Europe. In: INTERNATIONAL SYMPOSIUM ON DUST CONTROL IN ANIMAL PRODUCTION FACILITIES, 1., 1999, Aarhus-Denmark. Proceedings... Aarhus: Danish Institute of Agricultural Sciences, 1999. p.140-53. 